\title{
Nuclear magnetic resonance in chemical structures authentication and pyrolysis oil characterization
}

Fanxin Liu ( $\sim$ fanxin.liu45@yahoo.com )

Shantou University

Wujun Zeng

Shantou University

Yinglei Wei

Shantou University

\section{Research Article}

Keywords: nuclear magnetic resonance, pyrolysis oil, chemical structures, bio-oil

Posted Date: January 6th, 2022

DOI: https://doi.org/10.21203/rs.3.rs-1229563/v1

License: (1) This work is licensed under a Creative Commons Attribution 4.0 International License.

Read Full License 


\title{
Nuclear magnetic resonance in chemical structures authentication and pyrolysis oil characterization
}

\author{
Fanxin Liu ${ }^{\text {a,* }}$, Wujun Zenga, Yinglei Wei ${ }^{\mathrm{a}}$ \\ ${ }^{a}$ Department of Chemistry, College of Science, Shantou University, Shantou, Guangdong, China
}

*Corresponding author: Fanxin Liu, Department of Chemistry, College of Science, Shantou University, Shantou, Guangdong, China

\begin{abstract}
Nuclear Magnetic Resonance (NMR) involves the study of nuclei immersed in a static magnetic field and exposed to a second oscillating field. Nuclei have two properties; spin properties and charge properties. Pyrolysis oil is created by dry heating biomass in a reactor without oxygen to around 500 degrees Celsius and then cooling it. Pyrolysis oil is a type of tar that includes too much oxygen to be classified as a pure hydrocarbon. One of the most fundamental methods in synthetic chemistry is using NMR to verify chemical structure. In the literature, little attention has been paid to the application of NMR in the authentication of chemical structures. In this study, we present a use case of NMR to characterize pyrolysis oil and authenticate chemical structures. Results show that the elucidation of chemical compositions of bio-oil is essential for the optimization of its processing technology and exploration of its potential application.
\end{abstract}

Keywords: nuclear magnetic resonance (NMR), pyrolysis oil, chemical structures, bio-oil

\section{Introduction}

The study of nuclei immersed in a static magnetic field and exposed to a second pulsating field is known as nuclear magnetic resonance (NMR). Spin properties and charge properties are two 
properties of nuclei. Nuclei are made of protons and neutrons; both have spin values of $1 / 2$. Protons give charge. Only atoms with an odd number of protons or neutrons have spin because pairs of spins tend to cancel out $[1,2]$. If a nucleus possesses both angular momentum and a magnetic moment, it has the NMR property.

Washburn et al. [3] offered a new method for measuring T1 and T1-T2 correlations using solid echoes that solve some of the issues with NMR experiments on shale samples vs. traditional reservoir rocks. When these approaches were combined with conventional T1 and T2 measurements, a more comprehensive picture of the hydrogen-bearing materials (e.g., bitumen, kerogen, clay-bound water) in shale samples were obtained. These procedures were used to analyze the solid and very dense organic phases present throughout the petroleum production process in immature and pyrolyzed oil shale samples. In comparison to standard techniques, actual echo measurements provide more signal in oil shale samples, suggesting the existence of components conducting homonuclear dipolar coupling. The first low-field NMR observations on kerogen are described here, as well as a comprehensive NMR investigation of very viscous thermally produced bitumen found in pyrolyzed oil shale.

Ben et al. [4] analyzed the chemical shift assignment of 27 different $\mathrm{C}-\mathrm{H}$ bonds found in the pyrolysis oils based on databases and the HSQC-NMR spectrum data analysis. The HSQC-NMR examination of these pyrolysis oils revealed two types of methoxyl groups present in the pyrolysis oils made from lignin and pine wood, indicating that the lignin's natural methoxyl group rearranges during thermal treatment. The amount of aromatic $\mathrm{C}-\mathrm{H}$ and aliphatic $\mathrm{C}-\mathrm{H}$ bonds in the pyrolysis oils formed from lignin and pine wood rose with higher pyrolysis temperatures. The pyrolysis oils made from cellulose and pinewood were discovered to include levoglucosan as one of the principal components, and the cellulose pyrolysis oils had furfurals and phenols as well. The lignin component formed the majority of aromatic and aliphatic $\mathrm{C}-\mathrm{H}$ linkages in the pinewood pyrolysis oils. Their findings show that HSQC-NMR is capable of providing in-depth investigation of pyrolysis oils.

In this study, we show how NMR may be used to describe pyrolysis oil and verify chemical structures. The remainder of the paper is structured as follows. We first present the materials and methods used to conduct the experiments. Then, we present the results and compare our findings with the related studies in the literature. The findings suggest that understanding the chemical 
compositions of bio-oil is critical for improving its processing technology and exploring its possible applications.

\section{Materials and Methods}

Some nuclei have an odd number of protons or neutrons. After the magnetic field is applied, some protons or neutrons align against the magnetic field, while others align with the applied area. The following equation gives the difference between the two energy states:

$\Delta \mathrm{E}=\mathrm{\gamma hB}_{0} / 2 \pi$

Where $\mathrm{B}_{0}$ is the external magnetic field, $\mathrm{h}$ is Plank's constant, and $\mathrm{y}$ is the gyromagnetic ratio. The gyromagnetic ratio is critical for NMR. It allows us to calculate the Energy needed to change an atomic nucleus from the low to high-energy state in a given magnetic field.

$\Delta \mathrm{E}=\mathrm{hu}=\mathrm{\gamma hB} / 2 \pi$

$\mathrm{u}=\mathrm{\gamma hB} / 2 \pi \mathrm{h}$

This frequency (v) is known as Larmor frequency. It is the same as the precession frequency of the nucleus. For a particular atomic nucleus, the resonance frequency is constant and proportionate to magnetic field intensity [5-7]. Not much information could be obtained if all protons absorb the same amount of energy in the given magnetic field. On the other hand, Protons are shielded from the external field by electrons. The induced magnetic field created by circulating electrons opposes the external magnetic field. The magnetic field must be raised for a protected proton to flip at the same frequency. Depending on their chemical environment, protons in a molecule are shielded by different amounts, as shown in Fig. 1.

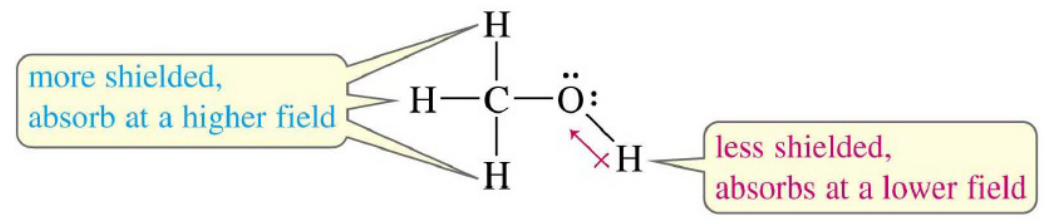

Fig. 1. Protons shielded in a molecule 
The use of nuclear magnetic resonance in NMR spectroscopy concerning hydrogen-1 nuclei inside the molecules of a material to identify the structure of its molecules is known as proton nuclear magnetic resonance (proton NMR, hydrogen-1 NMR, or 1H NMR). Fig. 2 shows how those protons appear on NMR spectra.

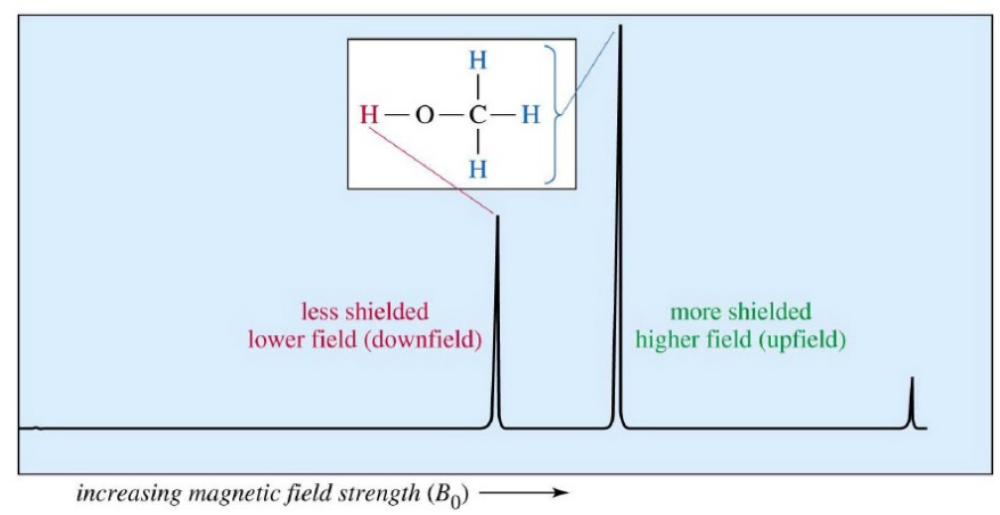

Fig. 2. NMR peak positions of differently shielded protons

In Fig. 2, the number of signals shows how many different kinds of protons are present. The location of signals shows how shielded or deshielded the proton is. The intensity of the signal shows the number of protons of that type. Signal splitting shows the number of protons on the adjacent atom. Once we stop applying Energy, the net magnetization will be aligned with static field $\mathbf{B}_{0}$. This process is called relaxation. So the part of net magnetization perpendicular to $\mathbf{B}_{\mathbf{0}}$ shrinks. This part provides a detectable signal. This signal is transformed from the time domain to frequency domain using Fourier transform [8-10].

Both proton NMR and ${ }^{13} \mathrm{C}$ NMR on feed biooil and improved biooil are required in the field of bio-oil and biofuel. ${ }^{13} \mathrm{C}$ NMR is also based on the same principles as ${ }^{1} \mathrm{H}$ NMR. However, it is about 6000 times less sensitive than ${ }^{1} \mathrm{H}$ due to the very low natural abundance of $1.1 \%$ of $13 \mathrm{C}$ and that's why we use a more significant number of scans for ${ }^{13} \mathrm{C}$ NMR [11-13]. It also offers immediate information on the organic molecule's backbone.

NMR analysis would be complementary to FT-IR in confirming hydrogenation. Molecules with permanent dipole moments are I.R. active, as shown in Fig. 3. NMR focuses on structural investigation of hydrocarbon molecules, while FT-IR is based on distinctive vibrational 
frequencies of bonds that include stretching and bending vibrations. NMR is an essential tool for group type analysis, i.e., it directly measures aromatic and aliphatic carbons $\left({ }^{13} \mathrm{C} N M R\right)$ and hydrogen distribution ( ${ }^{1} \mathrm{H}$ NMR). It also gives crucial information about a molecule's carbon and hydrogen structural grouping [14-19]. Integration of relevant portions of the ${ }^{13} \mathrm{C}$ and ${ }^{1} \mathrm{H}$ NMR spectra can be used to determine a quantitative assessment of oxygen-containing functions [20, 21]. During hydrogenation, hydrogen attacks chemical bonds, causing them to become saturated or broken. The structural modifications of the molecules will be tracked by NMR, while FT-IR will study changes in chemical bonding.



Fig. 3. Examples of I.R. active and I.R. inactive bonds

It also allows researchers to follow the energy content of hydrogenation products by identifying the functional group compositions of upgraded biooil and comparing NMR results to feed biooil, gasoline, and diesel. According to certain research, NMR may also be used to test the thermal stability of biooil and biodiesel. For example, ${ }^{13} \mathrm{C}$ NMR examination of hydrotreated biooils with various oxygen concentrations that were used to generate light naphtha, jet, diesel, and gas oil revealed that the presence of polymeric material with slow molecular movements causes a vast peak in the spectra. [21, 22].

\section{Results and Discussion}

The rise in the heating value of biooil owing to hydrogenation might be explained using NMR. The amount of HHV increase may be determined using a bomb calorimeter. Still, NMR provides more precise information on why the HHV has grown by considering the number of hydrocarbon structures (aliphatics, aromatics, etc.) that contribute to increasing the heating value. I'd also anticipate linking the number of hydrocarbon groups acquired through semiquantification of NMR spectra to the upgraded biooil's heating value [23-25]. The computations that follow will help to 
elucidate this assertion. First, assume Table 1 contains the NMR data from three tests comparing the feed bio-oil to the feed biooil. The HHV of the feed biooil and the upgraded biooil were 27.65 $\mathrm{MJ} / \mathrm{Kg}$ and $42.23 \mathrm{MJ} / \mathrm{Kg}$, respectively, in an experiment with a $10 \%$ biooil to catalyst ratio at $500^{\circ} \mathrm{C}$. Assume that there is a straightforward relationship (equation 4) between the HHV of the end products that consider the average HHV of each fraction (as shown in Table 2) to determine the HHV of the upgraded biooil.

$\mathrm{HHV}=\sum \mathrm{x}_{\mathrm{i}} \cdot \mathrm{k}_{\mathrm{i}} \cdot \mathrm{HHV}_{\mathrm{i}}$

Where $x_{i}$ is the area fraction obtained from NMR semiquantification results, $\mathrm{k}_{\mathrm{i}}$ is a contribution factor specific to hydrocarbon fraction $i$, and $\mathrm{HHV}_{\mathrm{i}}$ is the heating value of fraction $\mathrm{i}$.

Table 1. Results for ${ }^{13} \mathrm{C}$ NMR spectral integration

\begin{tabular}{|c|c|c|c|c|c|c|}
\hline \multirow[b]{2}{*}{$\begin{array}{l}\text { Chemical } \\
\text { shift region } \\
\text { (ppm) }\end{array}$} & \multirow[b]{2}{*}{$\begin{array}{l}\text { Dominant type } \\
\text { of carbon }\end{array}$} & \multicolumn{5}{|c|}{ Experimental condition } \\
\hline & & Feed biooil & $\begin{array}{c}10 \% \\
\text { catalyst- } \\
300 \mathrm{C} \\
\end{array}$ & $\begin{array}{c}10 \% \\
\text { catalyst- } \\
400 \mathrm{C} \\
\end{array}$ & $\begin{array}{c}10 \% \\
\text { catalyst- } \\
500 \mathrm{C} \\
\end{array}$ & $\begin{array}{c}15 \% \\
\text { catalyst- } \\
400 \mathrm{C} \\
\end{array}$ \\
\hline $0-28$ & $\begin{array}{l}\text { saturated } \\
\text { aliphatic } \\
\text { groups }\end{array}$ & 16.86 & 26.00 & 49.17 & 57.30 & 58.55 \\
\hline $28-55$ & $\begin{array}{l}\text { unsaturated } \\
\text { aliphatic } \\
\text { groups }\end{array}$ & 10.55 & 8.52 & 3.71 & 2.77 & 3.60 \\
\hline $55-95$ & $\begin{array}{l}\text { ethers, phenolic } \\
\text { methoxys, } \\
\text { anhydrosugars }\end{array}$ & 13.10 & 10.40 & 10.20 & 5.45 & 7.91 \\
\hline $95-165$ & $\begin{array}{l}\text { aromatics, } \\
\text { furans } \\
\text { organic }\end{array}$ & 56.77 & 52.34 & 16.28 & 34.25 & 29.45 \\
\hline $165-180$ & $\begin{array}{l}\text { (carboxylic) } \\
\text { acids, esters }\end{array}$ & 1.58 & 1.57 & 1.03 & 0.10 & 0.34 \\
\hline $180-215$ & $\begin{array}{l}\text { ketones, } \\
\text { aldehydes }\end{array}$ & 1.10 & 1.16 & 1.03 & 0.10 & 0.11 \\
\hline
\end{tabular}

We would have six equations with six unknowns if we did six experiments (contribution factors). The unknowns in this system of equations might be simply solved. The results of the contribution factor calculations are shown in Table 3. 
Table 2. Average HHV of hydrocarbon fractions

\begin{tabular}{cc}
\hline Hydrocarbon fraction & Avg. HHV (M.J./Kg) \\
\hline saturated aliphatic groups & 48.61 \\
unsaturated aliphatic groups & 45.30 \\
alcohols, ethers, phenolic & 29.71 \\
methoxys, anhydrosugars & 41.8 \\
aromatics, furans & 23.14 \\
organic (carboxylic) acids, & 27.51 \\
esters & \\
\hline
\end{tabular}

Table 3. Calculated $k_{i}$ for each fraction

\begin{tabular}{cc}
\hline Hydrocarbon fraction & $\mathrm{k}_{\mathrm{i}}$ \\
\hline saturated aliphatic groups & 0.98 \\
unsaturated aliphatic groups & 0.82 \\
alcohols, ethers, phenolic \\
methoxys, anhydrosugars \\
$\begin{array}{c}\text { aromatics, furans } \\
\text { organic (carboxylic) acids, } \\
\text { esters }\end{array}$
\end{tabular}

Substituting area fractions, k-values, and HHVs into equation 1 for the data obtained from the experiment with $10 \%$ catalyst loading at $500{ }^{\circ} \mathrm{C}$ gives the following result:

$\mathrm{HHV}=(0.57 \times 0.98 \times 48.61)+(0.03 \times 0.82 \times 45.3)+(0.05 \times 0.18 \times 29.71)+(0.34 \times 0.95 \times 41.8)+$ $(0.001 \times 0.41 \times 23.14)+(0.001 \times 0.26 \times 27.51)=\mathbf{4 2 . 2 3} \mathrm{MJ} / \mathrm{kg}$ 
The HHV in this computation line is the same as in the bomb calorimeter. In addition to bomb calorimetry measurements, NMR results would provide a descriptive confirmation of HHV rise $[26,27]$. Thermochemical conversion of bio-feedstocks typically yields gas (hydrogen), solids (biochar), and, most critically, a two-phase liquid (aqueous and organic) [28-30]. Each product has the capability of increasing the value of the parent feedstock. The upgrading of bio-oil involves several processes (examples are shown in Fig. 4). For example, we may track the efficacy and performance of modified red mud for hydrogenation and compare the upgraded products derived from red mud as catalyst and $\mathrm{Ni}$ /Silica-Alumina to determine the best parameters for red mud modification. Furthermore, studying lignocellulosic biomass at the model compound level (e.g., using guaiacol and 5-HMF as reaction representations) might offer important information about the thermochemical behavior of parent cellulose, hemicellulose, or lignin [31-34].

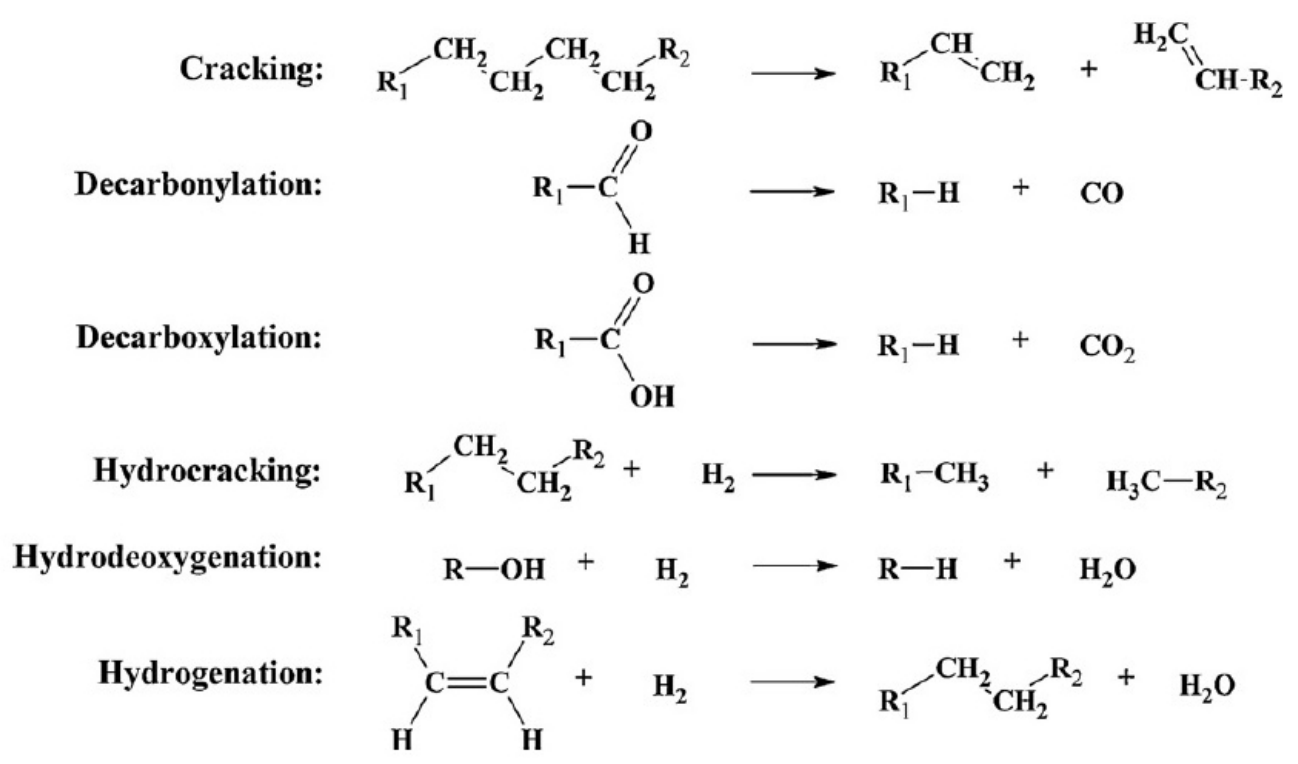

Fig. 4. Examples of reactions associated with catalytic bio-oil upgrading $[35,36]$.

Assume NMR findings of feed biooil and enhanced bio-oils utilizing modified red mud and $\mathrm{Ni} /$ silica-alumina as catalysts are shown in Table 4. 
Table 4. Comparison of catalytic performance of Ni/silica-alumina and modified red mud at $10 \%$ catalyst loading and $500{ }^{\circ} \mathrm{C}[12,37]$.

\begin{tabular}{|c|c|c|c|c|}
\hline \multirow{2}{*}{$\begin{array}{l}\text { Chemical shift } \\
\text { region (ppm) }\end{array}$} & \multirow{2}{*}{$\begin{array}{l}\text { Dominant type of } \\
\text { carbon }\end{array}$} & \multicolumn{3}{|c|}{ Catalyst } \\
\hline & & Feed biooil & $\mathrm{Ni} /$ silica-alumina & $\begin{array}{l}\text { Modified red } \\
\text { mud catalyst }\end{array}$ \\
\hline $0-28$ & $\begin{array}{l}\text { saturated aliphatic } \\
\text { groups }\end{array}$ & 16.86 & 57.30 & 63.49 \\
\hline $28-55$ & $\begin{array}{l}\text { unsaturated } \\
\text { aliphatic groups }\end{array}$ & 10.55 & 2.77 & 2.91 \\
\hline $55-95$ & $\begin{array}{l}\text { alcohols, ethers, } \\
\text { phenolic } \\
\text { methoxys, } \\
\text { anhydrosugars }\end{array}$ & 13.10 & 5.45 & 6.22 \\
\hline $95-165$ & $\begin{array}{c}\text { aromatics, furans } \\
\text { organic }\end{array}$ & 56.77 & 34.25 & 25.76 \\
\hline $165-180$ & $\begin{array}{c}\text { (carboxylic) acids, } \\
\text { esters }\end{array}$ & 1.58 & 0.10 & 0.10 \\
\hline $180-215$ & $\begin{array}{l}\text { ketones, } \\
\text { aldehydes }\end{array}$ & 1.10 & 0.10 & 1.50 \\
\hline
\end{tabular}

Table 4 reveals that the modified catalyst produces more aliphatic hydrocarbons than Ni/silicaalumina. Still, it has fewer aromatics, indicating that modified red mud can saturate aromatic rings better than $\mathrm{Ni} /$ silica-alumina. So we will be looking for the optimum modification parameters, such as the best nickel salt to red mud ratio during impregnation if nickel salt is utilized to change the red mud.

According to the global energy forecast (2020), energy consumption in this industry is predicted to increase by at least $80 \%$ over the next several decades. However, because the estimates offered here were all made before COVID-19, they do not consider the tremendous worldwide developments that have transpired in recent months [38-41]. Nonetheless, jet fuel and diesel consumption are mostly to blame for this predicted increase. Saturated aromatics, resins, and asphaltenes (SARA fractions) are the four primary petroleum fractions. Asphaltenes are the least desirable of the four [42-46]. Asphaltenes can block the transfer lines and are extremely recalcitrant to biodegradation. Gasoline is a mixture of different hydrocarbon fractions. Gasoline typically contains $4-8 \%$ alkanes, 2-5\% alkenes, 24-40\% isoalkanes, 3-7\% cycloalkanes, 1-4\% cycloalkenes, $20-50 \%$ total aromatics $\left(0.5-2.5 \%\right.$ benzene). Gasoline includes $\mathrm{C}_{5}$ to $\mathrm{C}_{13}$ 
hydrocarbons, while diesel includes $\mathrm{C}_{14}$ to $\mathrm{C}_{19}[47,48]$. Because gasoline contains largely aliphatic and aromatic hydrocarbons, we must adjust the experimental conditions to maximize the aliphatic and aromatic fractions in the upgraded biooil. The ${ }^{13} \mathrm{C}$ NMR spectra in this example was recorded on a JEOL $300 \mathrm{MHz}$ NMR spectrometer (JEOL, Ltd., Tokyo, Japan). About $0.2 \mathrm{~g}$ of oil is dissolved in $0.6 \mathrm{~g}$ deuterated dimethyl sulfoxide- $\mathrm{d}_{6}\left(\mathrm{DMSO}^{\left.-\mathrm{d}_{6}\right)}\right.$ in a $5-\mathrm{mm}$ sample probe. The DMSO-d6 containing $1 \%(\mathrm{v} / \mathrm{v})$ tetramethylsilane (TMS) is obtained from Sigma-Aldrich (Sigma-Aldrich, St. Louis, MO, USA). The observing frequency for the ${ }^{13} \mathrm{C}$ nucleus is 100.58 $\mathrm{MHz}$, the pulse width is $10 \mu \mathrm{s}$, the acquisition time is $1.58 \mathrm{~s}$, and the relaxation delay is $2 \mathrm{~s}$. The spectra will be acquired with 4000 scans and a $20 \mathrm{kHz}$ sweep width. Figures 5-7 show the NMR spectra of three samples that demonstrate how hydrogenation has been efficient in improving biooil. Analysis of HDO organic liquids using 13C NMR. Semiquantitative integration of 13C NMR spectra was used to describe the functional groups present in crude bio-oil and HDO oils. Chemical shifts for various functional groups were assigned based on those found in the literature. Carbohydrate breakdown products, alcohols, ethers, methoxylated phenols, carboxylic groups, aldehydes, and ketones were abundant in the crude bio-oil. Due to hydrogenation of unsaturated aliphatics, HDO of alcohols, ethers, carboxylic acids, aldehydes, and ketones, the distinctive peaks at $0-28 \mathrm{ppm}$ ascribed to saturated aliphatic carbon atoms increased. Because of better hydrogenation/hydrodeoxygenation of unsaturated and oxygenated molecules, increasing the $\mathrm{Ni}$ loading from $10 \%$ to $40 \%$ increased the saturated aliphatic carbon atoms from 24.7 percent to 42.6 percent. The unsaturated carbon atoms separated from oxygen atoms by at least two bonds had chemical shifts of $28-55 \mathrm{ppm}$ in the bio-oil, and their presence in the HDO oil rose as the $\mathrm{Ni}$ content of the catalyst increased. Aliphatic carbon atoms connected to oxygen atoms in alcohols, esters, and anhydrous carbohydrates were ascribed chemical shifts of 55-95 ppm. Due to improved catalytic activity, increasing Ni loading reduced the number of alcohols, esters, and anhydrous carbohydrates $[49,50]$. At Ni loadings of $40 \%, 50 \%$, and $65 \%$, no peaks were seen at chemical shifts between 55-95 ppm, implying that all oxygenated molecules, including the methoxy carbon, resonate at $55-57 \mathrm{ppm}$ were completely deoxygenated.

Aromatic carbon atoms in phenolic compounds and furans were allocated to the typical peaks with 95-165 ppm chemical shifts. Due to the hydrogenation/deoxygenation of these compounds, the number of carbon atoms in these compounds reduced as Ni loading increased. When Ni loading was increased from $40 \%$ to 65 percent, unsaturated aliphatics increased from $17.6 \%$ to $27.6 \%$, 
while aromatic compounds decreased from $39.8 \%$ to $16.2 \%$. These findings might be explained by partial hydrogenation of aromatic compounds. Due to enhanced hydrogenation of unsaturated aliphatics, the saturated aliphatics content increased from 42.6 percent to 56.2 percent. Even at 65 percent Ni loading, however, hydrogenation of unsaturated aliphatics was not complete. Longer reaction periods may result in full hydrogenation of unsaturated aliphatic carbons, but they are also known to produce hydrocracking of organic compounds into gases, lowering the organic liquid yield. At large Ni loadings, the chemical shifts at 165-180 ppm attributed to carboxylic acids and esters rapidly diminished and eventually vanished. The strength of these carboxylic carbon signals reduced from 5.3 percent to 1.4 percent when the $\mathrm{Ni}$ dosage was increased from $10 \%$ to $30 \%$. Because of full deoxygenation of these compounds at higher Ni loadings, no typical peaks between 165-180 ppm were seen.

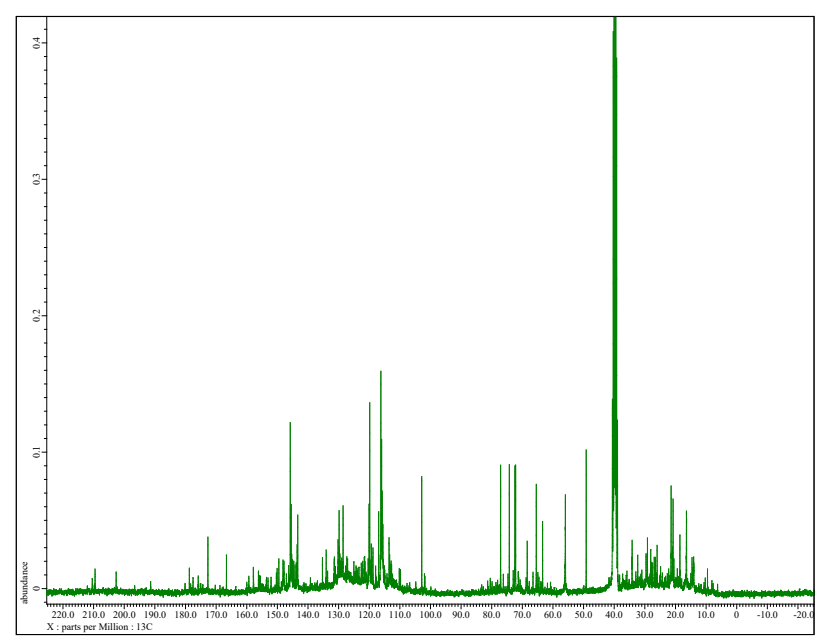

Fig. 5. NMR spectra of the feed bio-oil 




Fig. 6. NMR spectra of hydrogenated biooil using $10 \%$ catalyst to biooil ratio under $400^{\circ}$

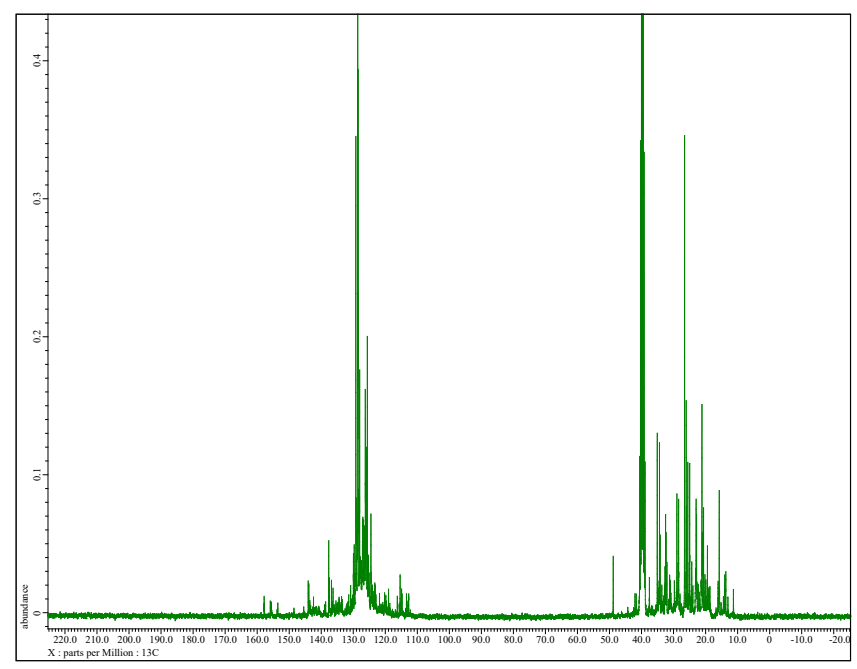

Fig. 7. NMR spectra of hydrogenated bio-oil using $10 \%$ catalyst to bio-oil ratio under $500{ }^{\circ} \mathrm{C}$

NMR enables quantitative examination of the entire bio-oil sample, rather than just a subset, and provides information on the chemical functional groups present. In this approach, NMR characterization of pyrolysis bio-oil can aid in determining the best operating parameters for the pyrolysis process and identifying acceptable (alternative) feedstocks for creating chemically stable bio-oils over long periods. The bulk of chemicals found in bio-oils, on the other hand, have relatively low concentrations $(<0.2 \mathrm{wt} . \%)$, and a detailed compositional analysis requires the 
combination of several techniques such as 2-dimensional NMR, GC $\times$ MS $\times$ MS, and FT $\times$ ICR $\times$ MS [51-53]. NMR techniques are most potent in identifying pure-chemical chemicals and crossconfirmation of GC-MS results. Proton and carbon NMR can be used to trace down the formation of hydrocarbons in the aqueous phase, bio-oil epoxidation, and other chemical changes, for example. The aromatics, alkanes, epoxidized compounds, internal olefins, and phenol formaldehyde derivatives were authenticated using 13C NMR and comparing them to legitimate standards due to their great purity [54-56].

\section{Conclusion}

Understanding biochemical oil's composition is critical for optimizing its processing technology and exploring its possible applications. The most powerful techniques for bio-oil characterization have been deemed comprehensive 2-D G.C. and ultrahigh-resolution M.S., the most sophisticated technology in related disciplines. FTIR and NMR spectroscopy might also give information on the functional and skeletal structure components. Advanced NMR spectroscopy methods may be able to provide a more objective overall view of the complicated bio-oil samples. FTIR spectroscopy and G.C. are less expensive than HRMS and NMR spectroscopy, making them suitable options. Furthermore, as compared to lignin, the high Mw fractions exhibit a novel structural networkbased mostly on guaiacol/ disubstituted aromatic ethers and polyaromatic hydrocarbon structures bonded closely together, as revealed by 2D and 13C NMR studies. The discovery of novel macromolecules in the higher Mw fractions suggests that LignoBoost ${ }^{\mathrm{TM}} \mathrm{kraft}$ lignin is solvated in the subcritical phase and can undergo processes including depolymerization of $\mathrm{C}-\mathrm{O}$ and $\mathrm{C}-\mathrm{C}$ linkages, as well as repolymerization into heavier Mw fragments, heavy oil, and suspended solids.

\section{References}

1. Harris RK. Nuclear magnetic resonance spectroscopy. 1986.

2. Hore PJ. Nuclear magnetic resonance: Oxford University Press, USA; 2015.

3. Washburn KE, Birdwell JE. Updated methodology for nuclear magnetic resonance characterization of shales. Journal of Magnetic Resonance. 2013;233:17-28. 
4. Ben H, Ragauskas AJ. Heteronuclear single-quantum correlation-nuclear magnetic resonance (HSQC-NMR) fingerprint analysis of pyrolysis oils. Energy \& Fuels. 2011;25(12):5791-801.

5. Bovey FA, Mirau PA, Gutowsky H. Nuclear magnetic resonance spectroscopy: Elsevier; 1988.

6. Stewart WE, Siddall TH. Nuclear magnetic resonance studies of amides. Chemical Reviews. 1970;70(5):517-51.

7. McConnell HM. Reaction rates by nuclear magnetic resonance. The Journal of chemical physics. 1958;28(3):430-1.

8. Ernst RR, Bodenhausen G, Wokaun A. Principles of nuclear magnetic resonance in one and two dimensions: Clarendon press Oxford; 1987.

9. Leksell L, Leksell D, Schwebel J. Stereotaxis and nuclear magnetic resonance. Journal of Neurology, Neurosurgery \& Psychiatry. 1985;48(1):14-8.

10. SHEN C-C, CHANG Y-S, HO L-K. Nuclear-magnetic-resonance studies of 5, 7dihydroxyflavonoids. Phytochemistry. 1993;34(3):843-5.

11. Leonardis I, Chiaberge S, Fiorani T, Spera S, Battistel E, Bosetti A, et al. Characterization of bio-oil from hydrothermal liquefaction of organic waste by NMR spectroscopy and FTICR mass spectrometry. ChemSusChem. 2013;6(1):160-7.

12. Jahromi H, Agblevor FA. Hydrodeoxygenation of aqueous-phase catalytic pyrolysis oil to liquid hydrocarbons using multifunctional nickel catalyst. Industrial \& Engineering Chemistry Research. 2018;57(39):13257-68.

13. Schnitzer MI, Monreal CM, Facey GA, Fransham PB. The conversion of chicken manure to biooil by fast pyrolysis I. Analyses of chicken manure, biooils and char by $13 \mathrm{C}$ and 1H NMR 
and FTIR spectrophotometry. Journal of Environmental Science and Health Part B. 2007;42(1):717.

14. Cody GD, Alexander CMD. NMR studies of chemical structural variation of insoluble organic matter from different carbonaceous chondrite groups. Geochimica et Cosmochimica Acta. 2005;69(4):1085-97.

15. Jahromi R, Rezaei M, Samadi SH, Jahromi H. Biomass gasification in a downdraft fixedbed gasifier: Optimization of operating conditions. Chemical Engineering Science. 2021;231:116249.

16. Hontoria-Lucas C, López-Peinado A, López-González JdD, Rojas-Cervantes M, MartínAranda R. Study of oxygen-containing groups in a series of graphite oxides: physical and chemical characterization. Carbon. 1995;33(11):1585-92.

17. Panda R, Hsieh M, Chung R, Chin T. FTIR, XRD, SEM and solid state NMR investigations of carbonate-containing hydroxyapatite nano-particles synthesized by hydroxide-gel technique. Journal of Physics and Chemistry of Solids. 2003;64(2):193-9.

18. Lotsch BV, Döblinger M, Sehnert J, Seyfarth L, Senker J, Oeckler O, et al. Unmasking melon by a complementary approach employing electron diffraction, solid-state NMR spectroscopy, and theoretical calculations - structural characterization of a carbon nitride polymer. Chemistry-A European Journal. 2007;13(17):4969-80.

19. Jahromi HJ, Eskandari K, Alizadeh A. Comparison of halogen bonds in $\mathrm{M}-\mathrm{X} \cdots \mathrm{N}$ contacts $(\mathrm{M}=\mathrm{C}, \mathrm{Si}, \mathrm{Ge}$ and $\mathrm{X}=\mathrm{Cl}$, Br). Journal of molecular modeling. 2015;21(5):1-9.

20. He Z, Honeycutt CW, Xing B, McDowell RW, Pellechia PJ, Zhang T. Solid-state Fourier transform infrared and 31P nuclear magnetic resonance spectral features of phosphate compounds. Soil Science. 2007;172(7):501-15. 
21. Morris KF, Johnson Jr CS. Diffusion-ordered two-dimensional nuclear magnetic resonance spectroscopy. Journal of the American chemical society. 1992;114(8):3139-41.

22. Louden D, Handley A, Taylor S, Lenz E, Miller S, Wilson ID, et al. Spectroscopic characterisation and identification of ecdysteroids using high-performance liquid chromatography combined with on-line UV-diode array, FT-infrared and 1H-nuclear magnetic resonance spectroscopy and time of flight mass spectrometry. Journal of Chromatography A. 2001;910(2):237-46.

23. Elliott DC, Neuenschwander GG, Hart TR, Hu J, Solana AE, Cao C. Hydrogenation of bio-oil for chemicals and fuels production. Pacific Northwest National Laboratory (PNNL), Richland, WA (US ...; 2006.

24. Wang S, Wang Y, Cai Q, Wang X, Jin H, Luo Z. Multi-step separation of monophenols and pyrolytic lignins from the water-insoluble phase of bio-oil. Separation and Purification Technology. 2014;122:248-55.

25. Jahromi R, Pakravan HA, Saidi MS, Firoozabadi B. Primary stenosis progression versus secondary stenosis formation in the left coronary bifurcation: A mechanical point of view. Biocybernetics and Biomedical Engineering. 2019;39(1):188-98.

26. Jiang X, Zhong Z, Ellis N, Wang Q. Aging and Thermal Stability of the Mixed Product of the Ether-Soluble Fraction of Bio-Oil and Bio-Diesel. Chemical Engineering \& Technology. 2011;34(5):727-36.

27. Leng F, Wang Y, Chen J, Wang S, Zhou J, Luo Z. Characterization of pyrolytic lignins with different activities obtained from bio-oil. Chinese Journal of Chemical Engineering. 2017;25(3):324-9. 
28. Harun K, Adhikari S, Jahromi H. Hydrogen production via thermocatalytic decomposition of methane using carbon-based catalysts. RSC Advances. 2020;10(67):40882-93.

29. Bridgwater AV, Meier D, Radlein D. An overview of fast pyrolysis of biomass. Organic geochemistry. 1999;30(12):1479-93.

30. Lapuerta M, Hernández JJ, Pazo A, López J. Gasification and co-gasification of biomass wastes: Effect of the biomass origin and the gasifier operating conditions. Fuel processing technology. 2008;89(9):828-37.

31. Jahromi H, Agblevor FA. Hydrotreating of guaiacol: A comparative study of Red mudsupported nickel and commercial Ni/SiO2-A12O3 catalysts. Applied Catalysis A: General. 2018;558:109-21.

32. Mattsson C, Andersson S-I, Belkheiri T, Åmand L-E, Olausson L, Vamling L, et al. Using 2D NMR to characterize the structure of the low and high molecular weight fractions of bio-oil obtained from LignoBoost ${ }^{\mathrm{TM}}$ kraft lignin depolymerized in subcritical water. Biomass and bioenergy. 2016;95:364-77.

33. Croce A, Battistel E, Chiaberge S, Spera S, Reale S, De Angelis F. Mass Spectrometry and Nuclear Magnetic Resonance Spectroscopy study of carbohydrate decomposition by hydrothermal liquefaction treatment: A modeling approach on bio-oil production from organic wastes. Energy \& Fuels. 2015;29(9):5847-56.

34. Zhang J, Wang K, Nolte MW, Choi YS, Brown RC, Shanks BH. Catalytic deoxygenation of bio-oil model compounds over acid-base bifunctional catalysts. ACS Catalysis. 2016;6(4):2608-21.

35. Mortensen PM, Grunwaldt J-D, Jensen PA, Knudsen K, Jensen AD. A review of catalytic upgrading of bio-oil to engine fuels. Applied Catalysis A: General. 2011;407(1-2):1-19. 
36. Ruddy DA, Schaidle JA, Ferrell III JR, Wang J, Moens L, Hensley JE. Recent advances in heterogeneous catalysts for bio-oil upgrading via "ex situ catalytic fast pyrolysis": catalyst development through the study of model compounds. Green Chemistry. 2014;16(2):454-90.

37. Jahromi H, Agblevor FA. Hydrodeoxygenation of pinyon-juniper catalytic pyrolysis oil using red mud-supported nickel catalysts. Applied Catalysis B: Environmental. 2018;236:1-12.

38. Newell RG, Raimi D. Global energy outlook comparison methods: 2020 update. Resources for the Future; 2020.

39. Gillingham KT, Knittel CR, Li J, Ovaere M, Reguant M. The Short-run and Long-run Effects of Covid-19 on Energy and the Environment. Joule. 2020;4(7):1337-41.

40. Jahromi R, Mogharab V, Jahromi H, Avazpour A. Synergistic effects of anionic surfactants on coronavirus (SARS-CoV-2) virucidal efficiency of sanitizing fluids to fight COVID-19. Food and Chemical Toxicology. 2020;145:111702.

41. Kuzemko C, Bradshaw M, Bridge G, Goldthau A, Jewell J, Overland I, et al. Covid-19 and the politics of sustainable energy transitions. Energy Research \& Social Science. 2020;68:101685. 42. Islas-Flores C, Buenrostro-Gonzalez E, Lira-Galeana C. Comparisons between open column chromatography and HPLC SARA fractionations in petroleum. Energy \& fuels. 2005;19(5):2080-8.

43. Ashoori S, Sharifi M, Masoumi M, Salehi MM. The relationship between SARA fractions and crude oil stability. Egyptian Journal of Petroleum. 2017;26(1):209-13.

44. Jahromi H, Fazaelipoor M, Ayatollahi S, Niazi A. Asphaltenes biodegradation under shaking and static conditions. Fuel. 2014;117:230-5.

45. Verstraete JJ, Schnongs P, Dulot H, Hudebine D. Molecular reconstruction of heavy petroleum residue fractions. Chemical Engineering Science. 2010;65(1):304-12. 
46. Nikooee E, Amin JS, Ayatollahi S, Alamdari A, Jahromi H, Escrochi M, editors. Fractal Analysis of Surface Roughness Induced by Asphaltene Deposits: Effect of Surface Topography on Wettability Altera. Shiraz 2009-1st EAGE International Petroleum Conference and Exhibition; 2009: European Association of Geoscientists \& Engineers.

47. Jahromi H, Adhikari S, Roy P, Hassani E, Pope C, Oh T-S, et al. Production of green transportation fuels from Brassica carinata oil: A comparative study of noble and transition metal catalysts. Fuel Processing Technology. 2021;215:106737.

48. Vempatapu BP, Kanaujia PK. Monitoring petroleum fuel adulteration: A review of analytical methods. TrAC Trends in Analytical Chemistry. 2017;92:1-11.

49. Jahromi H, Agblevor FA. Upgrading of pinyon-juniper catalytic pyrolysis oil via hydrodeoxygenation. Energy. 2017;141:2186-95.

50. Aboulkas A, Hammani H, El Achaby M, Bilal E, Barakat A. Valorization of algal waste via pyrolysis in a fixed-bed reactor: production and characterization of bio-oil and bio-char. Bioresource technology. 2017;243:400-8.

51. Sanguineti MM, Hourani N, Witt M, Sarathy SM, Thomsen L, Kuhnert N. Analysis of impact of temperature and saltwater on Nannochloropsis salina bio-oil production by ultra high resolution APCI FT-ICR MS. Algal Research. 2015;9:227-35.

52. Patil V, Adhikari S, Cross P, Jahromi H. Progress in the solvent depolymerization of lignin. Renewable and Sustainable Energy Reviews. 2020;133:110359.

53. Butler E, Devlin G, Meier D, McDonnell K. Fluidised bed pyrolysis of lignocellulosic biomasses and comparison of bio-oil and micropyrolyser pyrolysate by GC/MS-FID. Journal of Analytical and applied pyrolysis. 2013;103:96-101. 
54. Celikbag Y, Meadows S, Barde M, Adhikari S, Buschle-Diller G, Auad ML, et al. Synthesis and characterization of bio-oil-based self-curing epoxy resin. Industrial \& Engineering Chemistry Research. 2017;56(33):9389-400.

55. $\mathrm{Yu} \mathrm{Y,} \mathrm{Xu} \mathrm{P,} \mathrm{Chang} \mathrm{M,} \mathrm{Chang} \mathrm{J.} \mathrm{Aging} \mathrm{properties} \mathrm{of} \mathrm{phenol-formaldehyde} \mathrm{resin} \mathrm{modified}$ by bio-oil using uv weathering. Polymers. 2018;10(11):1183.

56. Jahromi H, Adhikari S, Roy P, Shelley M, Hassani E, Oh T-S. Synthesis of novel biolubricants from waste cooking oil and cyclic oxygenates through an integrated catalytic process. ACS Sustainable Chemistry \& Engineering. 2021;9(40):13424-37. 